\title{
Survival of patients with subglottic squamous cell carcinoma
}

\author{
S.D. MacNeil MD MSc, ${ }^{+\dagger}$ K. Patel MD, ${ }^{*}$ K. Liu, ${ }^{\dagger}$ S. Shariff $\mathrm{PhD}^{\dagger}{ }^{\dagger}$ J. Yoo MD, ${ }^{*}$ A. Nichols MD, ${ }^{*}$ K. Fung MD, ${ }^{*}$ \\ and A.X. Garg MD PhD ${ }^{\dagger \ddagger \S}$
}

\begin{abstract}
Objective Subglottic squamous cell carcinoma is a rare subsite of laryngeal cancer that behaves more aggressively and portends a worse prognosis. Using a population-based cancer registry, our objective was to report overall survival (os) and laryngectomy-free survival (LFS) in patients diagnosed with subglottic squamous cell carcinoma, and to determine whether primary laryngectomy results in improved survival.

Methods This retrospective population-based study considered patients with a new diagnosis of squamous cell carcinoma in the province of Ontario over a 15-year period (1995-2009). The Ontario Cancer Registry was examined for patients with the diagnosis of interest during the period of interest. Linked population-based databases were used to obtain patient demographics, comorbidity measures, staging, survival, and primary treatment with laryngectomy.

Results Of 4927 patients identified to have laryngeal carcinoma, 89 were defined as having primary subglottic carcinoma (1.8\%). In the subglottic cohort, 68 patients were men (76.4\%), and mean age at diagnosis was 68 years (interquartile range: $60-77$ years). The 5 -year os was $47.2 \%$, and the 5 -year LFs was $31.5 \%$. In 13 patients (15\%), the primary treatment was laryngectomy, which, compared with primary radiation, did not predict for improved os. No differences in os or LFS were observed during the 15-year study period ( $\operatorname{os} p=0.42$, LFS $p=0.83$ ).
\end{abstract}

Conclusions The survival of patients with subglottic carcinoma is poor and has remained stable over time (19952009). Compared with primary radiation, primary treatment with laryngectomy does not appear to improve os.

Key Words Head-and-neck cancer, larynx, radiation therapy, outcomes

Curr Oncol. 2018 Dec;25(6):e569-e575

www.current-oncology.com

\section{INTRODUCTION}

Squamous cell carcinoma (scc) of the subglottis is rare, representing less than $5 \%$ of all laryngeal cancer ${ }^{1,2}$. In the past, separating primary subglottic cancer from glottic cancer with subglottic extension was challenging because of poor imaging and laryngoscopy equipment ${ }^{3}$. The superior anatomic boundary of the subglottis has also been inconsistently defined, ranging from $5 \mathrm{~mm}$ to $1 \mathrm{~cm}$ below the lateral margin of the ventricle, further complicating accurate classification of this disease subsite ${ }^{4}$. The rarity of the disease, the historic difficulty in separating primary from secondary subglottic cancer, and the changing definition of the superior boundary have made it challenging to report treatment and survival outcomes for this rare carcinoma.
Secondary to advanced stage at presentation, propensity for paratracheal and upper mediastinal lymphatic spread, and increased risk of stomal recurrence, primary subglottic SCC is thought to herald a prognosis worse than that for other subsites of laryngeal cancer ${ }^{5-9}$. Historically, total laryngectomy has been the standard of care for the treatment of subglottic carcinoma ${ }^{3}$. More recent retrospective studies have demonstrated comparable survival outcomes for patients treated with primary radiotherapy ${ }^{2,10-12}$. However, those studies are limited by institutional selection bias, incomplete surgical data, and lack of laryngectomy-free survival (LFS) as an outcome $e^{2,10-12}$. Whether radiation is equivalent to primary laryngectomy as a treatment option remains unknown. Similarly, there is no evidence to suggest that the apparent increased use 
of radiotherapy over time has resulted in an improvement in LFS in this patient population.

The purpose of the present study was to report overall survival (os) and LFs outcomes for patients diagnosed with subglottic scc in Ontario over a 15-year period and to determine whether primary laryngectomy results in an improved os.

\section{METHODS}

\section{Study Design and Setting}

Residents of Ontario (2014 population estimate: $13,678,700)^{13}$ have universal access to hospital care and physician services. Those encounters are recorded in large population-based health care databases, many of which are held at the Institute for Clinical Evaluative Sciences. We conducted a population-based retrospective cohort study of all patients with laryngeal carcinoma. The study was approved by the Sunnybrook Health Sciences Centre research ethics board.

\section{Data Sources}

We used five linked databases: the Ontario Cancer Registry, which records data for all patients with non-skin cancers diagnosed in Ontario (mandatory reporting) ${ }^{14,15}$; the Discharge Abstract Database held by the Canadian Institute for Health Information, which records all admissions to hospitals and includes information about diagnoses and procedures performed; the OHIP (Ontario Health Insurance Plan) database, which contains information about all feefor-service physician claims for inpatient and outpatient services; the Registered Persons Database, which contains vital statistics about all permanent residents of Ontario; and the National Ambulatory Care Reporting System Database, which collects data about ambulatory care visits, including day surgery, outpatient clinics, cancer clinics, and emergency department visits. The databases were linked using unique encoded identifiers (encrypted Ontario health care numbers that are unique to each resident eligible for health care services paid by the government) available starting July 1991, after the assignment of new health care numbers in Ontario.

We previously used those data sources to study secular trends in other conditions ${ }^{16,17}$. For the present work, we used the Ontario Cancer Registry to identify laryngeal cancer patients (subsite subglottis), and the Discharge Abstract Database, National Ambulatory Care Reporting System, OHIP database, and Registered Persons Database to define patient characteristics, baseline comorbidities, and patient outcomes. Diagnoses were identified using the codes defined by the International Classification of Diseases, 9th revision (pre-2002), and 10th revision (post2002). Procedures were identified using the codes defined in the Canadian Classification of Diagnostic, Therapeutic, and Surgical Procedures (pre-2002) and the Canadian Classification of Health Interventions (post-2002).

\section{Patients}

All patients with a diagnosis of laryngeal cancer and scc on histology during 1995-2009 in the province of Ontario were retrospectively reviewed. To allow for a complete 3-year look-back for baseline comorbidities, cohort accrual began 1 January 1995 . We restricted the cohort to patients who were residents of Ontario and who had a histologic diagnosis of scc. A prior validation study found a sensitivity of $89.8 \%$ and a positive predictive value of $96.8 \%$ for the diagnostic code for laryngeal cancer in the registry compared with a clinical database ${ }^{18}$. The date of the laryngeal cancer diagnosis ("index date") served as the start time for follow-up.

Patients were further divided into groups for supraglottic, glottic, and subglottic cancers. Staging data were available only for the subpopulation diagnosed from 2005 to 2009. Registry staging ranged from I to IV and was derived from the American Joint Committee on Cancer staging manual (6th or 7 th edition) ${ }^{4}$. We classified patients with stage I or II disease as "early stage." According to both versions of the staging manual, the early-stage grouping included patients with local disease only and excluded patients with regional or distant metastases. Patients with stage III or IV disease were classified as "advanced stage." That group included patients with advanced local disease and patients with regional or distant metastasis. Patients who underwent laryngectomy within 3 months of the initial diagnosis were considered to be have been treated with primary laryngectomy. We assumed that 3 months would allow enough time to capture patients whose treatment was delayed for other medical problems, but would be too soon for radiation failure to be identified (assuming 6- to 7-week course of radiation). Patients who underwent laryngectomy after 3 months were considered to have experienced radiotherapy failure requiring a salvage laryngectomy. Those not treated with primary laryngectomy were assumed to have been treated with primary radiation.

\section{Outcomes}

We categorized the study period into three eras: 1995-1999, 2000-2004, and 2005-2009. We selected those eras to correspond to the availability of staging data, which began in 2004. Thus, the cohort was allocated into 3 approximately equal periods. We determined 5 -year mortality after a subglottic cancer diagnosis for each of the 3 eras and the rate per 100 person-years. We assessed 2 primary outcomes in the 5 years after a new diagnosis of laryngeal cancer: os and LFs. We defined os as the proportion of patients alive at 5 years from the date of diagnosis, censoring for patients who were lost to follow-up before 5 years. We defined LFs as the proportion of patients alive at 5 years from the date of diagnosis with an intact larynx, censoring for patients who were lost to follow-up. Deaths (including out-of-hospital mortality) are well ascertained in the Registered Persons Database, which provides accurate mortality data for all Ontario residents ${ }^{19}$.

\section{Statistical Analysis}

For each of the defined eras and for the 15-year overall period, mean age with standard deviation, age group $(\leq 64$ years, $\geq 65$ years), sex, Charlson comorbidity group $(0,1$, $\geq 2$ ), and treatment (laryngectomy, salvage laryngectomy, radiation) are reported. To determine whether the demographic characteristics of the patients differed in each era, the Kruskal-Wallis test for continuous variables was applied. 
We determined the crude 5-year mortality for patients after a subglottic cancer diagnosis and calculated the rate per 100 person-years. Kaplan-Meier plots adjusting for age group, Charlson comorbidity group, and sex (male/female) were generated for both 5-year os and 5-year LFs.

For the patients in each of the 3 eras, Kaplan-Meier plots were generated for both 5-year os and 5-year LFs. We used the log-rank test to determine whether a difference was evident between the 3 eras for each survival outcome.

We used the PHREG procedure in the SAS software application (version 9.3: SAS Institute, Cary, NC, U.S.A.) to create a Cox proportional hazards regression model investigating the association between treatment with surgery or radiation and survival, adjusting for the influence of potential confounders (age, sex, and Charlson comorbidity group).

SAS was used for all statistical analyses. We interpreted 2-tailed $p$ values less than 0.05 as statistically significant.

\section{RESULTS}

\section{Cohort Description and Demographics}

From 1995 to 2009, 4977 patients in Ontario were diagnosed with laryngeal cancer. Of that group, 50 patients were excluded because of insufficient information, leaving 4927 patients, 1371 of whom $(27.83 \%)$ were diagnosed supraglottic cancer; 3201 (64.97\%), with glottic cancer; and 89 (1.81\%), with subglottic cancer (Figure 1).

Of the 89 patients with subglottic cancer, 31 were diagnosed during 1995-1999, 31 during 2000-2004, and 27 during 2005-2009. Table I reports the baseline characteristics of those patients. Mean age at diagnosis was 68 years, and 68 of the patients were men (76.4\%). Primary laryngectomy was used to treat 13 patients (14.6\%); 15 patients (16.9\%) underwent salvage laryngectomy; and 61

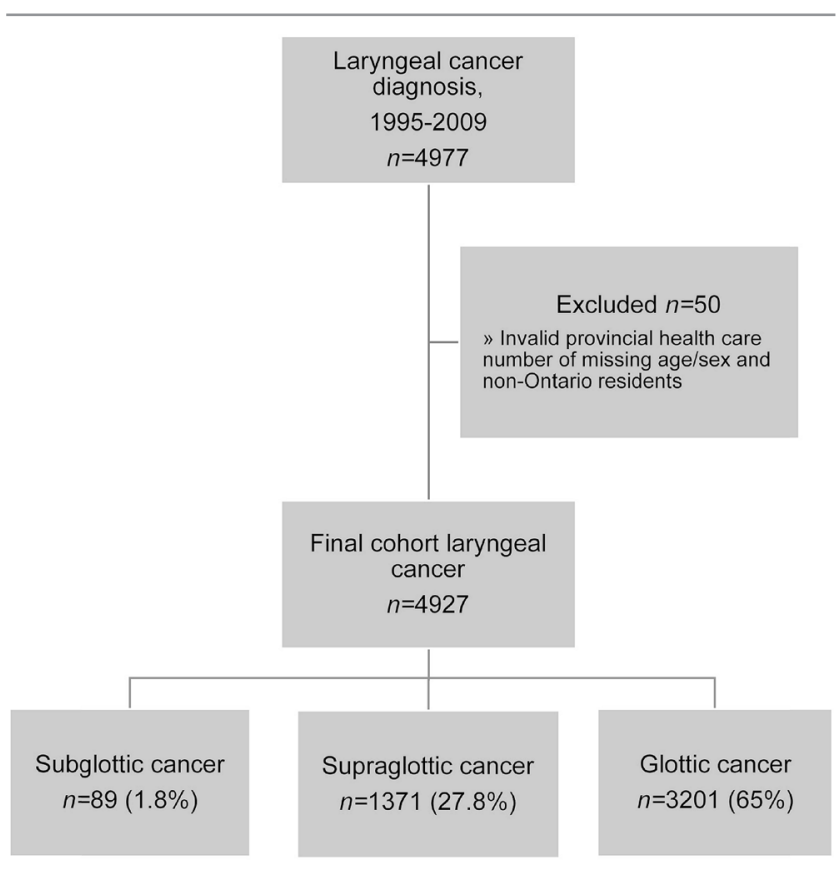

FIGURE 1 Selection of patients for the subglottic cancer cohort. patients $(68.5 \%)$ did not undergo laryngectomy within 5 years of diagnosis. The number of patients who underwent laryngectomy did not differ in the 3 eras $(p=0.23)$.

\section{Five-Year Survival Trends}

Table II outlines the 5-year mortality after a diagnosis of subglottic cancer. The 5-year mortality was $58.06 \%$ (18/31) during 1995-1999, 41.94\% (13/31) during 2000-2004, and $59.26 \%$ (16/27) during 2005-2009. Mortality rates were not significantly different in the 3 diagnosis eras $(p=0.42)$. For the cohort overall, the 5 -year os was $47.2 \%$, and the 5 -year LFS was $31.5 \%$ (Figures 2 and 3).

\section{Survival Analysis}

Results of the survival analysis indicate that age $(\geq 65$ years vs. $\leq 64$ years) is a significant predictor of 5-year mortality (hazard ratio: 2.57 ; 95\% confidence interval: 1.25 to 5.26 ; Table III). No significant difference in 5-year mortality was observed for patients treated with primary laryngectomy compared with those treated with primary radiation (hazard ratio: 1.21 ; 95\% confidence interval: 0.55 to 2.67 ).

\section{DISCUSSION}

In the Canadian province of Ontario, subglottic scc represented $1.8 \%$ of all new diagnoses of laryngeal cancer during 1995-2009. The 5-year os for the subglottic site was $47.2 \%$ compared with $57.4 \%$ for the other laryngeal subsites ${ }^{16}$. During the 15-year period of interest, we observed no improvement in os or LFS. Furthermore, we found no difference in survival between patients treated with primary laryngectomy and those treated with primary radiotherapy.

TABLE I Baseline characteristics of 89 patients in Ontario with subglottic squamous cell cancer, 1995-2009

\begin{tabular}{|c|c|c|}
\hline & Variable & Value \\
\hline & lean age (years) & $68.0 \pm 11.1$ \\
\hline \multicolumn{3}{|c|}{ Age group $[n(\%)]$} \\
\hline & $<65$ Years & $32(35.9)$ \\
\hline & $\geq 65$ & $57(64.0)$ \\
\hline & $\operatorname{ex}[n(\%) \operatorname{men}]$ & $68(76.4)$ \\
\hline \multicolumn{3}{|c|}{ Stage $^{\mathrm{a}}(n)$} \\
\hline & $\mathrm{I} / \mathrm{II}$ & 12 \\
\hline & III/IV & $\leq 15$ \\
\hline \multicolumn{3}{|c|}{ Treatment $[n(\%)]$} \\
\hline & Primary laryngectomy ${ }^{b}$ & $13(14.6)$ \\
\hline & Radiation ${ }^{\mathrm{c}}$ & $61(68.5)$ \\
\hline & Salvage laryngectomy ${ }^{d}$ & $15(16.9)$ \\
\hline \multicolumn{3}{|c|}{ Staging information was available only for 2005-2009. } \\
\hline \multicolumn{3}{|c|}{$\begin{array}{l}\text { Defined as patients undergoing laryngectomy within } 3 \text { months of } \\
\text { the date of diagnosis. }\end{array}$} \\
\hline c & \multicolumn{2}{|c|}{$\begin{array}{l}\text { Radiation codes were unavailable. We therefore assumed that, if } \\
\text { patients did not undergo primary laryngectomy, they had been } \\
\text { treated with radiation. However, patients who received no treatment } \\
\text { might also have been included in this group. }\end{array}$} \\
\hline \multicolumn{3}{|c|}{$\begin{array}{l}\text { Defined as patients undergoing laryngectomy more than } 3 \text { months } \\
\text { after the date of diagnosis. }\end{array}$} \\
\hline
\end{tabular}




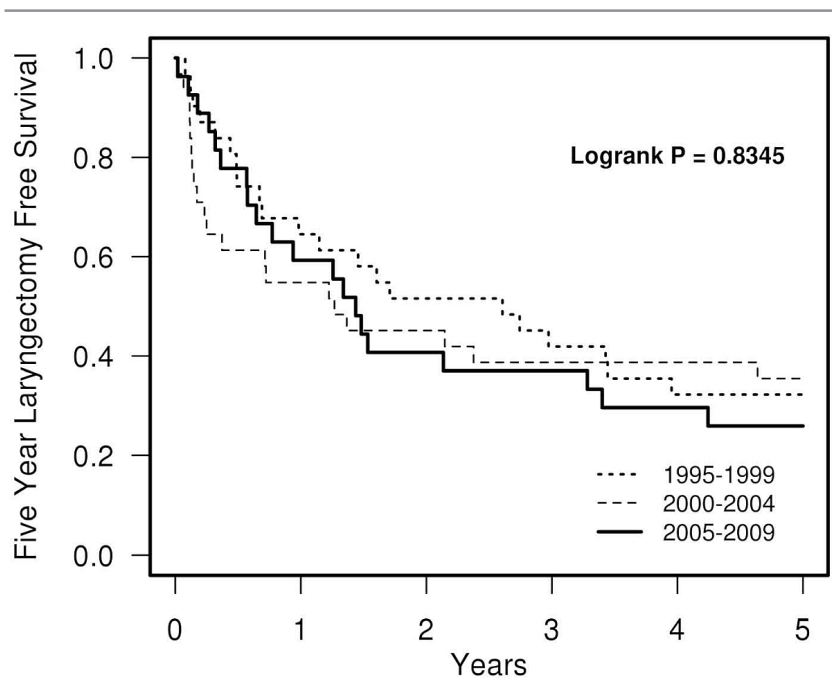

FIGURE 2 Kaplan-Meier plot depicting 5-year laryngectomy-free survival.

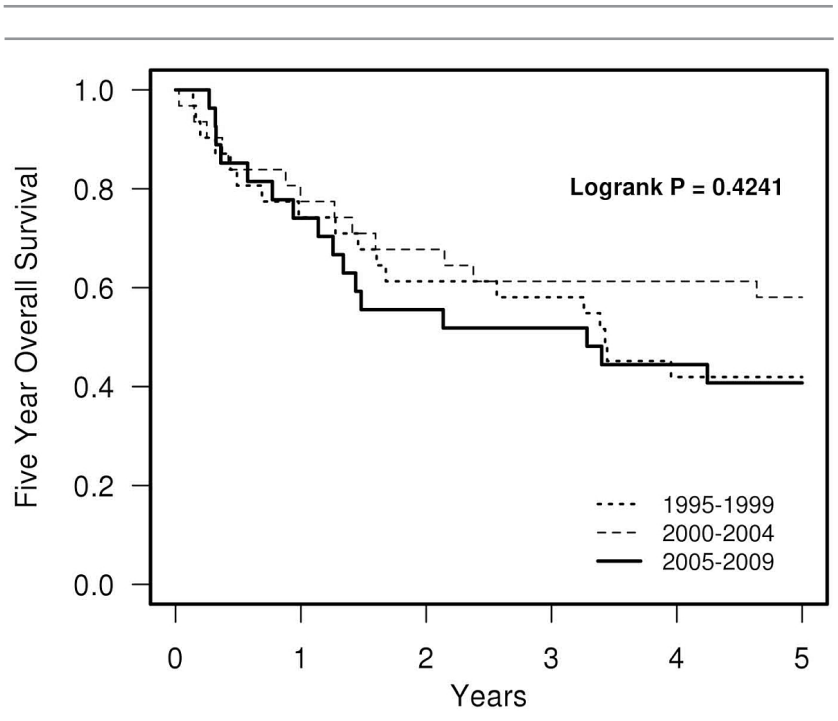

FIGURE 3 Kaplan-Meier plot depicting 5-year overall survival.

\section{Subglottic Carcinoma Characteristics}

The demographic characteristics of the study patients are consistent with those reported in other studies, demonstrating the face validity of the present work $1,5,16,20$. Subglottic carcinoma in our cohort represented $1.8 \%$ of all laryngeal sccs. Other studies have found incidence rates in the range of $1.0 \%-8.7 \%$ for subglottic laryngeal sCC, although most studies report a range $1 \%-1.6 \% 5,20,21$. Variability in the definition of primary subglottic scc over time and the inclusion of cancers of other histology in the definition of subglottic scc is the likely reason for the discrepancy in the incidence reported here compared with other series ${ }^{10,21-23}$.

Primary subglottic carcinoma is usually asymptomatic early in the disease process and is traditionally thought to present at an advanced stage $(50 \%-64 \% \text { of patients })^{2,5,8,11}$. However, we found an even distribution between patients presenting with early-stage and advanced-stage disease. The small number of patients in our series and lack of
TABLE II Five-year mortality after a diagnosis of subglottic cancer

\begin{tabular}{cccc}
\hline $\begin{array}{c}\text { Diagnosis } \\
\text { period }\end{array}$ & $\begin{array}{c}\text { Patients } \\
(\boldsymbol{n})\end{array}$ & $\begin{array}{c}\text { 5-Year mortality } \\
{[\boldsymbol{n}(\boldsymbol{\%})]}\end{array}$ & $\begin{array}{c}\text { Deaths per } \\
\mathbf{1 0 0} \text { person-years }\end{array}$ \\
\hline $1995-1999$ & 31 & $18(58.1)$ & 19 \\
$2000-2004$ & 31 & $13(41.9)$ & 12 \\
$2005-2009$ & 27 & $16(59.3)$ & 20 \\
\hline
\end{tabular}

TABLE III Mortality at 5 years after a diagnosis of subglottic squamous cell carcinoma

\begin{tabular}{|c|c|c|}
\hline Variable & Adjusted HR & $95 \% \mathrm{Cl}$ \\
\hline \multicolumn{3}{|l|}{ Age group } \\
\hline$<65$ & \multicolumn{2}{|c|}{1.0 (Reference) } \\
\hline$\geq 65$ & 2.57 & 1.25 to 5.26 \\
\hline \multicolumn{3}{|l|}{ Sex } \\
\hline Women & \multicolumn{2}{|c|}{1.0 (Reference) } \\
\hline Men & 1.26 & 0.62 to 2.56 \\
\hline \multicolumn{3}{|l|}{$\mathrm{CCl}$ group } \\
\hline 0 & \multicolumn{2}{|c|}{1.0 (Reference) } \\
\hline 1 & 1.09 & 0.32 to 3.67 \\
\hline$\geq 2$ & 1.97 & 0.86 to 4.50 \\
\hline \multicolumn{3}{|l|}{ Treatment group } \\
\hline Radiation & \multicolumn{2}{|c|}{1.0 (Reference) } \\
\hline Primary laryngectomy & 1.21 & 0.55 to 2.67 \\
\hline
\end{tabular}

$\mathrm{HR}=$ hazard ratio; $\mathrm{Cl}=$ confidence interval; $\mathrm{CCl}=$ Charlson comorbidity index.

staging information before 2005 probably accounts for the variability in stage presentation. The largest reported study of patients with subglottic scc demonstrated a $58.4 \%$ $(219 / 375)$ rate of advanced-stage presentation ${ }^{11}$. Taken together, those data indicate that patients are slightly more likely to present with advanced-stage than with earlystage disease.

\section{Subglottic Carcinoma Treatment}

The treatment options for primary subglottic carcinoma include surgery (laryngectomy or partial laryngectomy), radiation (with or without chemotherapy), or combination therapy. Direct extra-laryngeal extension, a circumferential pattern of intraluminal spread and cartilage invasion, means that few patients are candidates for partial laryngectomy as primary treatment ${ }^{24}$. With a few exceptions (patients undergoing partial or hemi-laryngectomy), most patients in other studies underwent total laryngectomy (Table IV). Other studies showed significant variability with respect to primary treatment administered (Table IV). In some studies, patients were treated with primary surgery $^{1,11,25,27}$; in others, most patients were treated with primary radiotherapy ${ }^{10,12,20,26,28}$. Furthermore, the indications for combined-modality treatment, adjuvant radiation, and salvage laryngectomy were often not reported.

In our study, 13 patients (14.6\%) underwent primary laryngectomy. Other reports in the literature describe 
TABLE IV Subglottic carcinoma treatment and survival outcomes in the literature

\begin{tabular}{|c|c|c|c|c|c|c|}
\hline \multirow[t]{2}{*}{ Reference } & \multirow{2}{*}{$\begin{array}{l}\text { Patients } \\
\text { (n) }\end{array}$} & \multicolumn{2}{|c|}{ Stage } & \multicolumn{2}{|c|}{ Treatment } & \multirow{2}{*}{$\begin{array}{c}\text { OS } \\
(5 \text {-year } \%)\end{array}$} \\
\hline & & Group & (n) & Protocol & (n) & \\
\hline \multirow[t]{2}{*}{ Vermund, $1970^{3, a}$} & \multirow[t]{2}{*}{185} & \multirow{2}{*}{\multicolumn{2}{|c|}{$N R$}} & $\mathrm{TL}^{\mathrm{a}}$ & 58 & 42 \\
\hline & & & & RT & 127 & 36 \\
\hline \multirow[t]{2}{*}{ Shaha and Shah, $1982^{25}$} & \multirow[t]{2}{*}{16} & $\mathrm{I} / \mathrm{II}$ & 3 & TL & 13 & 70 \\
\hline & & III/IV & 13 & PL & 3 & \\
\hline \multirow[t]{2}{*}{ Warde et al., $1987^{26}$} & \multirow[t]{2}{*}{23} & $\mathrm{I} / \mathrm{II}$ & 9 & RT & 22 & 26 \\
\hline & & III/IV & 14 & RT with sTL & 1 & \\
\hline \multirow[t]{2}{*}{ Guedea et al., $1991^{12}$} & \multirow[t]{2}{*}{6} & $1 / I I$ & 3 & RT & 4 & 33 \\
\hline & & III/IV & 3 & RT with sTL & 2 & $(4-$ year \%) \\
\hline \multirow[t]{2}{*}{ Haylock and Deutsch, $1993^{20}$} & \multirow[t]{2}{*}{23} & $\mathrm{I} / \mathrm{II}$ & 13 & RT & 21 & 58 \\
\hline & & III/IV & 10 & RT with sTL & 2 & \\
\hline \multirow[t]{7}{*}{ Dahm et al., $1998^{22}$} & \multirow[t]{7}{*}{28} & $\mathrm{I} / \mathrm{II}$ & 19 & $\mathrm{TL}$ & 10 & $58^{c}$ \\
\hline & & $\mathrm{III} / \mathrm{IV}$ & 9 & TL with aRT & 1 & \\
\hline & & & & $P L$ & 2 & \\
\hline & & & & PL with aRT & 2 & \\
\hline & & & & RT & 10 & \\
\hline & & & & RT with salvage $S x$ & 2 & \\
\hline & & & & Palliation & 1 & \\
\hline \multirow[t]{2}{*}{ Strome et al., $1999^{2}$} & \multirow[t]{2}{*}{$10^{\mathrm{d}}$} & $\mathrm{I} / \mathrm{II}$ & 5 & TL with aRT & 3 & 67 \\
\hline & & III/IV & 4 & RT & 6 & \\
\hline \multirow[t]{4}{*}{ Santoro et al., $2000^{27}$} & \multirow[t]{4}{*}{49} & $\mathrm{I} / \mathrm{II}$ & 17 & TL & 17 & $56^{e}$ \\
\hline & & III/IV & 32 & TL with aRT & 18 & \\
\hline & & & & RT & 6 & \\
\hline & & & & Palliation & 8 & \\
\hline \multirow[t]{3}{*}{ Paisley et al., $2002^{10}$} & 43 & $\mathrm{I} / \mathrm{II}$ & 23 & RT & 29 & 50 \\
\hline & & III/IV & 20 & RT with sTL & 13 & \\
\hline & & & & CRT & 1 & \\
\hline Garas and McGuirt, $2006^{1}$ & 15 & $\mathrm{I} / \mathrm{II}$ & 3 & $\mathrm{TL}$ & 3 & $25^{f}$ \\
\hline & & III/IV & 12 & TL with aRT & 6 & \\
\hline & & & & RT & 4 & \\
\hline & & & & RT with sTL & 2 & \\
\hline Smee et al., $2008^{5}$ & 10 & $1 / I I$ & 6 & $\mathrm{TL}$ & 1 & 70 \\
\hline & & III/IV & 4 & TL with aRT & 4 & \\
\hline & & & & PL with aRT & 1 & \\
\hline & & & & RT & 4 & \\
\hline Hata et al., $2013^{28}$ & 19 & $\mathrm{I} / \mathrm{II}$ & 9 & RT & 5 & $80^{g}$ \\
\hline & & III/IV & 10 & CRT & 14 & \\
\hline Marchiano et al., $2016^{11}$ & 889 & $\mathrm{I} / \mathrm{II}$ & 126 & $S x^{h}$ & 139 & 41.5 \\
\hline & & III/IV & 219 & RT & 277 & \\
\hline & & & & Sx $x^{h}$ with $R T$ & 317 & \\
\hline & & & & Palliation & 85 & \\
\hline & & & & Unknown & 71 & \\
\hline Present study & 89 & $\mathrm{I} / \mathrm{II}$ & 12 & $\mathrm{TL}$ & 13 & 47 \\
\hline & & III/IV & 12 & RT & 76 & \\
\hline
\end{tabular}

a Literature review, including 20 studies. Some patients received adjuvant treatment.

c No difference in survival between treatment groups. The 5 -year overall survival was $44 \%$ for RT alone, $50 \%$ for surgery alone, and $100 \%$ for combined therapy.

d Staging was unavailable for 1 patient.

e The 5-year overall survival for patients treated with RT alone, with TL alone, or with TL and aRT was 0\%, 47\%, and $83.3 \%$ respectively. Survival was statistically significantly different for patients receiving TL with aRT compared with those receiving TL alone or RT alone $(p=0.001)$.

f The 3-year overall survival was $0 \%$ for patients treated with TL, $40 \%$ for those treated with TL and aRT, $33.3 \%$ for those treated with RT, and $0 \%$ for those treated with RT and sTL.

$\mathrm{g}$ The 5-year overall survival was 100\% for patients treated with CRT and 92\% for those treated with RT.

h Population-based study using U.S. Surveillance, Epidemiology, and End Results data that provided no further detail about the extent of surgery. $\mathrm{OS}=$ overall survival; $\mathrm{NR}=$ not reported; $\mathrm{TL}=$ total laryngectomy; $\mathrm{RT}=$ radiation therapy; $\mathrm{PL}=$ partial laryngectomy; $\mathrm{sTL}=$ salvage total laryngectomy; $\mathrm{aRT}=$ adjuvant radiation therapy; $\mathrm{Sx}=$ undefined surgery; $\mathrm{CRT}=$ chemoradiation therapy. 
$31 \%-81 \%$ of patients being treated with primary total laryngectomy and $10 \%-30 \%$ of patients being treated with partial laryngectomy ${ }^{1-3,5}$. We were not able to determine whether any patients in our cohort underwent partial laryngeal surgery. In our cohort, $68.5 \%$ of patients were managed non-surgically. Other studies reported $12 \%-100 \%$ of patients being treated with primary radiotherapy ${ }^{1-3,5,10,12,20,28}$. We did not have access to radiation or chemotherapy billing codes, and we therefore assumed that, if patients did not receive primary laryngectomy, they were treated with radiation. However, some of the latter patients could have been treated with palliative intent. Our reported rate of salvage laryngectomy was $16.9 \%$, but that number might have been larger, because some of the patients in the denominator might have been palliated. Data from our study and others do not make clear what proportion of patients treated with primary radiation required salvage laryngectomy and whether organ-preservation protocols improve LFS.

\section{Survival Outcomes}

We report a 5 -year os of $47.2 \%$ for the overall group of patients with a diagnosis of subglottic scc. Previous studies have reported 5 -year os rates ranging from $25 \%$ to $80 \%$ (Table IV). Some authors have suggested that a higher rate of local recurrence, particularly at the peristomal region, or a high rate of distant metastatic spread up to $32 \%$ is responsible for the poor os; however, the data are unclear $^{22}$. Earlier studies (Table IV) suggest that combinedmodality treatment-either surgery plus radiation, chemotherapy plus radiation, or radiation followed by salvage surgery-offers a survival benefit. However, small sample sizes prevent definitive conclusions from being drawn $n^{2,5,28}$. Limitations in our databases meant that we were unable to determine whether patients in our cohort received combined-modality treatment. Our results do, however, suggest that primary laryngectomy might not provide a survival benefit.

We observed no change in os or LFs from 1995 to 2009 (Figures 1 and 2). Those results are consistent with prior work by our group and others demonstrating no change in os in patients with glottic and supraglottic carcinomas $^{16,29-31}$. Although large randomized trials have demonstrated an improved LFs for patients with glottic and supraglottic carcinoma treated with concurrent chemoradiation, that benefit has not been demonstrated in population-based studies ${ }^{16,29,30}$. The reasons for the discrepancy are unknown, but could be related to patient selection for laryngeal-preservation protocols. Additionally, the difficulty in differentiating primary subglottic carcinoma from glottic carcinoma with subglottic extension and the evolving definition of the superior boundary of the subglottis could have influenced survival trends over the study period.

\section{Strengths and Limitations}

To our knowledge, the present study is the largest reported in the literature assessing the outcome of LFS in patients with subglottic carcinoma. Our survival outcome is robust, accounting for all patients with a diagnosis of subglottic carcinoma in the province of Ontario. That is, no selection bias is inherent in institutional reviews of survival outcomes. Procedural and diagnostic codes were well-documented ${ }^{18}$.

However, our study has limitations. We had only $\mathrm{T}$ stage and N stage information available for 2005-2009, and thus the stage analysis was limited. Furthermore, disease-specific survival was not calculated because cause of death has a low sensitivity in cancer registries and population databases. We assumed that patients who did not receive a primary laryngectomy were treated with primary radiation. Some of those patients might have been treated with palliative intent or might have received no treatment. Lack of radiation and chemotherapy treatment codes limited the analysis.

\section{CONCLUSIONS}

Compared with other laryngeal cancer subsites, subglottic carcinoma has a low incidence and a poor prognosis. The reason for poor os in patients with this subsite of laryngeal cancer is unknown, but appears to have no association with advanced stage at presentation. Overall, we observed no difference in the 5-year mortality rate for patients treated with primary laryngectomy and those treated without laryngectomy. Thus laryngeal preservation therapy could be considered a primary option for suitable patients. More research is needed to determine which patients are suitable for laryngeal-preservation treatment protocols and which should receive primary laryngectomy.

\section{ACKNOWLEDGMENTS}

This study was supported by the Institute for Clinical Evaluative Sciences (ICES) Western. An annual grant from the Ontario Ministry of Health and Long-Term Care (монLтc) funds ICEs. Core funding for ICES Western is provided by the Academic Medical Organization of Southwestern Ontario (aмоso), the Schulich School of Medicine and Dentistry (SSMD), Western University, and the Lawson Health Research Institute (LHRI). Our project was supported by a London Regional Cancer Program (LRCP) Catalyst Grant. The results, opinions, and conclusions are those of the authors and are independent from the funding sources. No endorsement by ICES, AMOSO, SSMD, LHRI, LRCP, Or MOHLTC is intended or should be inferred. The funding agencies had no role in the design and conduct of the study; collection, management, analysis, or interpretation of the data; preparation, review, or approval of the manuscript; nor in the decision to submit the manuscript for publication. The first author (SDM) had full access to all data in the study and takes responsibility for the integrity of the data and the accuracy of the data analysis.

\section{CONFLICT OF INTEREST DISCLOSURES}

We have read and understood Current Oncology's policy on disclosing conflicts of interest, and we declare that we have none.

\section{AUTHOR AFFILIATIONS}

*Department of Otolaryngology-Head and Neck Surgery, Western University, London, ON; 'Institute for Clinical Evaluative Sciences, Toronto, ON; ${ }^{\ddagger}$ Department of Epidemiology and Biostatistics, and ${ }^{\S}$ Division of Nephrology, Department of Medicine, Western University, London, ON.

\section{REFERENCES}

1. Garas J, McGuirt WF Sr. Squamous cell carcinoma of the subglottis. Am J Otolaryngol 2006;27:1-4. 
2. Strome SE, Robey TC, Devaney KO, Krause CJ, Hogikyan ND. Subglottic carcinoma: review of a series and characterization of its patterns of spread. Ear Nose Throat J 1999;78:622-624,626,628,passim.

3. Vermund H. Role of radiotherapy in cancer of the larynx as related to the TNM system of staging. A review. Cancer 1970;25:485-504.

4. Edge SB, Compton CC. The American Joint Committee on Cancer: the 7th edition of the AJCC Cancer Staging Manual and the future of TNM. Ann Surg Oncol 2009;17:1471-4.

5. Smee RI, Williams JR, Bridger GP. The management dilemmas of invasive subglottic carcinoma. Clin Oncol (R Coll Radiol) 2008;20:751-6.

6. Harrison DF. The pathology and management of subglottic cancer. Ann Otol Rhinol Laryngol 1971;80:6-12.

7. Kirchner JA. Two hundred laryngeal cancers: patterns of growth and spread as seen in serial section. Laryngoscope 1977;87:474-82.

8. Olofsson J, van Nostrand AW. Growth and spread of laryngeal and hypopharyngeal carcinoma with reflections on the effect of preoperative irradiation. 139 Cases studied by whole organ serial sectioning. Acta Otolaryngol Suppl 1973;308:1-84.

9. Bryce DP. The laryngeal subglottis. J Laryngol Otol 1975;89:667-85.

10. Paisley S, Warde PR, O'Sullivan B, et al. Results of radiotherapy for primary subglottic squamous cell carcinoma. Int $J$ Radiat Oncol Biol Phys 2002;52:1245-50.

11. Marchiano E, Patel DM, Patel TD, et al. Subglottic squamous cell carcinoma: a population-based study of 889 cases. Otolaryngol Head Neck Surg 2016;154:315-21.

12. Guedea F, Parsons JT, Mendenhall WM, Million RR, Stringer SP, Cassisi NJ. Primary subglottic cancer: results of radical radiation therapy. Int J Radiat Oncol Biol Phys 1991;21:1607-11.

13. Canadian Cancer Society's Advisory Committee on Cancer Statistics. Canadian Cancer Statistics 2013. Toronto, ON: Canadian Cancer Society; 2013.

14. Robles SC, Marrett LD, Clarke EA, Risch HA. An application of capture-recapture methods to the estimation of completeness of cancer registration. JClin Epidemiol 1988;41:495-501.

15. Clarke EA, Marrett LD, Kreiger N. Cancer registration in Ontario: a computer approach. IARC Sci Publ 1991;:246-57.

16. MacNeil SD, Liu K, Shariff SZ, et al. Secular trends in the survival of patients with laryngeal carcinoma, 1995-2007. Curr Oncol 2015;22:e85-99.
17. Siddiqui NF, Coca SG, Devereaux PJ, et al. Secular trends in acute dialysis after elective major surgery-1995 to 2009. CMAJ 2012;184:1237-45.

18. Hall S, Schulze K, Groome P, Mackillop W, Holowaty E. Using cancer registry data for survival studies: the example of the Ontario Cancer Registry. J Clin Epidemiol 2006;59:67-76.

19. Iron K, Zagorski B, Sykora K, Manuel DG. Living and Dying in Ontario: An Opportunity for Improved Health Information. Toronto, ON: Institute for Clinical Evaluative Sciences; 2008. [Available online at: https://www.ices.on.ca/Publications/ Atlases-and-Reports/2008/Living-and-dying-in-Ontario; cited 22 August 2015]

20. Haylock BJ, Deutsch GP. Primary radiotherapy for subglottic carcinoma. Clin Oncol (R Coll Radiol) 1993;5:143-6.

21. Sessions DG, Ogura JH, Fried MP. Carcinoma of the subglottic area. Laryngoscope 1975;85:1417-23.

22. Dahm JD, Sessions DG, Paniello RC, Harvey J. Primary subglottic cancer. Laryngoscope 1998;108:741-6.

23. Beahrs OH, Hensen DE, Hutter RVP, Kennedy BJ, eds. on behalf of the American Joint Committee on Cancer. Manual for Staging of Cancer. 4th ed. Philadelphia, PA: J.B. Lippincott Company; 1992.

24. Lund WS. Classification of subglottic tumors and discussion of their growth and spread. Can J Otolaryngol 1974;3:469-72.

25. Shaha AR, Shah JP. Carcinoma of the subglottic larynx. Am J Surg 1982;144:456-8.

27. Santoro R, Turelli M, Polli G. Primary carcinoma of the subglottic larynx. Eur Arch Otorhinolaryngol 2000;257:548-51.

26. Warde P, Harwood A, Keane T. Carcinoma of the subglottis. Results of initial radical radiation. Arch Otolaryngol Head Neck Surg 1987;113:1228-9.

28. Hata M, Taguchi T, Koike I, et al. Efficacy and toxicity of (chemo)radiotherapy for primary subglottic cancer. Strahlenther Onkol 2013;189:26-32.

29. Chen AY, Fedewa S, Zhu J. Temporal trends in the treatment of early- and advanced-stage laryngeal cancer in the United States, 1985-2007. Arch Otolaryngol Head Neck Surg 2011;137:1017-24.

30. Hoffman HT, Porter K, Karnell LH, et al. Laryngeal cancer in the United States: changes in demographics, patterns of care, and survival. Laryngoscope 2006;116(suppl 111):1-13.

31. Bezerra de Souza DL, Jerez Roig J, Bernal MM. Laryngeal cancer survival in Zaragoza (Spain): a population-based study. Clin Transl Oncol 2012;14:221-4. 